Correspondence

Jim Manos

jmanos@infdis.usyd.edu.au

Received 13 July 2008

Accepted 7 August 2008

\section{Transcriptome analyses and biofilm-forming characteristics of a clonal Pseudomonas aeruginosa from the cystic fibrosis lung}

Jim Manos, ${ }^{1}$ Jonathan Arthur, ${ }^{2,3}$ Barbara Rose, ${ }^{1}$ Pholawat Tingpej, ${ }^{1}$ Carina Fung, ${ }^{1}$ Michelle Curtis, ${ }^{1}$ Jeremy S. Webb, ${ }^{4,5}$ Honghua Hu, ${ }^{1}$ Staffan Kjelleberg, ${ }^{4}$ Mark D. Gorrell, ${ }^{6}$ Peter Bye ${ }^{2,7}$ and Colin Harbour ${ }^{1}$

\author{
${ }^{1}$ Department of Infectious Diseases and Immunology, University of Sydney, Sydney, Australia \\ ${ }^{2}$ Department of Medicine, University of Sydney, Sydney, Australia \\ ${ }^{3}$ Sydney Bioinformatics, University of Sydney, Sydney, Australia \\ ${ }^{4}$ School of Biotechnology and Biomolecular Sciences, University of New South Wales, Sydney, \\ Australia \\ ${ }^{5}$ School of Biological Sciences, University of Southampton, Southampton, UK \\ ${ }^{6}$ A. W. Morrow Gastroenterology and Liver Centre, Centenary Institute of Cancer Medicine and Cell \\ Biology, Royal Prince Alfred Hospital and Faculty of Medicine, University of Sydney, Sydney, \\ Australia \\ ${ }^{7}$ Department of Respiratory Medicine, Royal Prince Alfred Hospital, Sydney, Australia
}

Transmissible Pseudomonas aeruginosa clones potentially pose a serious threat to cystic fibrosis (CF) patients. The AES-1 clone has been found to infect up to $40 \%$ of patients in five CF centres in eastern Australia. Studies were carried out on clonal and non-clonal (NC) isolates from chronically infected CF patients, and the reference strain PAO1, to gain insight into the properties of AES-1. The transcriptomes of AES-1 and NC isolates, and of PAO1, grown planktonically and as a $72 \mathrm{~h}$ biofilm were compared using PAO1 microarrays. Microarray data were validated using real-time PCR. Overall, most differentially expressed genes were downregulated. AES-1 differentially expressed bacteriophage genes, novel motility genes, and virulence and quorum-sensing-related genes, compared with both PAO1 and NC. AES-1 but not NC biofilms significantly downregulated aerobic respiration genes compared with planktonic growth, suggesting enhanced anaerobic/microaerophilic growth by AES-1. Biofilm measurement showed that AES-1 formed significantly larger and thicker biofilms than NC or PAO1 isolates. This may be related to expression of the gene PA0729, encoding a biofilm-enhancing bacteriophage, identified by PCR in all AES-1 but few NC isolates $(n=42)$. Links with the Liverpool epidemic strain included the presence of PA0729 and the absence of the bacteriophage gene cluster PA0632-PA0639. No common markers were found with the Manchester strain. No particular differentially expressed gene in AES-1 could definitively be ascribed a role in its infectivity, thus increasing the likelihood that AES-1 infectivity is multifactorial and possibly involves novel genes. This study extends our understanding of the transcriptomic and genetic differences between clonal and NC strains of $P$. aeruginosa from CF lung.

\section{INTRODUCTION}

In cystic fibrosis (CF) patients, chronic Pseudomonas aeruginosa infection and inflammation are associated with biofilm formation, a progressive decline in lung function

Abbreviations: CF, cystic fibrosis; NC, non-clonal; OS, quorum sensing. and premature death (Al-Aloul et al., 2004; Koch \& Hoiby, 1993; Kosorok et al., 2001). Whilst most CF patients acquire non-clonal (NC) $P$. aeruginosa from the environment, genotyping has revealed the dissemination of $P$. aeruginosa clones within and between CF clinics in Britain, Australia (Armstrong et al., 2003; McCallum et al., 2002; Panagea et al., 2005; Scott \& Pitt, 2004) and Brazil 
(Pellegrino et al., 2006). Most CF clonal strains, apart from clone C (Romling et al., 1997), have not yet been found in the environment of the patient's home, the CF clinic or in the general environment, suggesting person-to-person spread. One such clone, the Australian epidemic strain-1 (AES-1, also designated Melbourne epidemic strain, m16 or PI), currently infects up to $40 \%$ of patients across five $\mathrm{CF}$ centres in mainland eastern Australia (Armstrong et al., 2002, 2003; O'Carroll et al., 2004).

The mechanisms of increased infectivity associated with clonal strains have not been defined and there are no clear indications to date of conserved processes across clonal strains. Potential processes may include acquisition or loss of genetic elements that confer adaptive or fitness advantages on cells (Brockhurst et al., 2005; Finnan et al., 2004; Klockgether et al., 2004). In an earlier study of the clonal CF Manchester strain (MA) (Lewis et al., 2005), its transmissibility (infectivity) was linked to the bacteriophage gene cluster designated Pf4 (Webb et al., 2004), highly homologous to the Pfl bacteriophage of $P$. aeruginosa located on a novel genomic island integrated adjacent to gene PA1014. Mutants of the wound isolate PAO1 (Stover et al., 2000) infected with Pf4 have shown significantly increased maximum biofilm thickness and microcolony area, compared with wild-type, in 3-day-old biofilms (Webb et al., 2004). Whilst gene acquisition may be an important factor in infectivity, the effect of expression differences occurring in shared genes should not be overlooked. Recently, Mathee et al. (2008) compared the genomes of a chronically infecting NC strain (strain PA2192) and the MA strain, and found that each carried a comparatively modest number of unique ORFs, representing approximately 9 and $1.3 \%$ of all ORFs, respectively. They thus inferred that, with over $90 \%$ of the genome being conserved, there is ample opportunity for expression of core genes, such as those held in common with PAO1, to play a role in the infectivity of the MA clonal strain.

Evidence that infectivity in some strains relates more to upregulation or downregulation of critical genes rather than to novel genes has come from the Liverpool epidemic strain (LES). LES exhibits increased expression of alkaline protease and elastase (Salunkhe et al., 2005). Changes in motility genes or genes that promote biofilm formation may also increase infectivity (O’Toole \& Kolter, 1998; Van Alst et al., 2007). Variants of $P$. aeruginosa possessing enhanced biofilmforming characteristics have frequently been detected both in vitro and in CF patients' sputum (Drenkard \& Ausubel, 2002), where $P$. aeruginosa exhibits microaerophilic or possibly anaerobic growth (Alvarez-Ortega \& Harwood, 2007; Platt et al., 2008). As infectivity is highly likely to be multi-factorial, both novel genes and differentially expressed genes present in other $P$. aeruginosa strains may be involved.

As a first step in characterizing AES-1, we compared the transcriptomes and biofilm-forming characteristics of AES1 and NC isolates from chronically infected CF patients. Isolates were grown in planktonic culture and as biofilms, and were compared with each other and with PAO1.

\section{METHODS}

Strains and isolates used in this study. Biofilm-forming studies and gene expression microarray analyses using PAO1 chips (Affymetrix) were conducted on eight $P$. aeruginosa $\mathrm{CF}$ isolates from the sputum of eight chronically infected patients attending the adult CF clinic at the Royal Prince Alfred Hospital, Sydney, Australia. Four of these isolates had previously been typed as AES-1 and four as NC by Spel macrorestriction followed by PFGE using established methods (Anthony et al., 2002). A clonal strain is defined here as having up to three band differences, following the criteria of Tenover et al. (1995). NC strains are defined as having more than three band differences. AES1 isolates were selected from patients with continuous infection with a $P$. aeruginosa strain for a minimum of 4 years and known infection with the same AES-1 isolate for at least 1 year. Patients with NC strains were matched as closely as possible with the AES-1 group for time of infection with the same $P$. aeruginosa NC strain and for gender and age (three female AES- 1 patients of $28.6 \pm 3.4$ years, with two female NC patients of $30.0 \pm 4.0$ years; one male AES- 1 patient of 22 years, with two male NC patients of $20.5 \pm 1.5$ years). The mean time of continuous infection with $P$. aeruginosa was 7.5 years (range 6-11 years) for the AES-1infected patients and 6.5 years (range $4-10$ years) for the NC-infected patients. Both planktonic and biofilm-grown PAO1 (ATCC 15692) (Stover et al., 2000) were also analysed by microarray.

Planktonic and biofilm-growth methods. Cells were inoculated from isolated colonies into $2 \mathrm{ml}$ Luria-Bertani (LB) broth. LB broth has been widely used as a non-specialized growth medium for planktonic $P$. aeruginosa transcriptomics in both $\mathrm{CF}$ and non-CF studies (Alvarez-Ortega \& Harwood, 2007; Salunkhe et al., 2005; Schuster et al., 2003; Waite et al., 2005). In accordance with the strategies adopted for transcriptome expression in other studies (Hentzer et al., 2005; Wagner et al., 2003), cells for planktonic growth were harvested at the mid-exponential phase $\left(\mathrm{OD}_{600}=0.5 \pm 0.05\right.$; Beckman DU640 Spectrophotometer), whilst biofilm-growth cells were harvested at $72 \mathrm{~h}$.

For biofilm measurement, mid-exponential-phase cells were inoculated $(1: 100)$ into $800 \mathrm{ml} \mathrm{LB}$ broth in a Centers for Disease Control and Protection (USA) Bioreactor and coupons were removed for staining with Syto9 (Molecular Probes) and image capture at 24, 48 and $72 \mathrm{~h}$ post-inoculation using fluorescence microscopy. Thickness measurements were conducted on the same biofilm samples from images taken using confocal microscopy. Ten randomly selected biofilms per isolate were measured (ImageJ software, version 1.38) for area and thickness, and the mean surface area and mean thickness covered by each isolate were calculated. Mean results for the two biological replicates per isolate were calculated and comparative statistical analyses between groups were performed (sPSs version 14.0) using an independent-samples $t$-test $(P<0.01)$. All isolates were grown and measured in duplicate, and viable cell counts were performed to ensure that consistent live cell numbers were inoculated into the bioreactor. To extract sufficient RNA for transcriptome analysis, coupons were replaced with attached glass slides to increase biofilm coverage. The assembly was incubated $\left(37{ }^{\circ} \mathrm{C}\right.$ in a water bath) and stirred (100 r.p.m.). At $72 \mathrm{~h}$ the biofilm was washed off using icecold $1 \times$ PBS. Cells were pelleted $\left(3 \mathrm{~min}, 5000 \mathrm{~g}, 4{ }^{\circ} \mathrm{C}\right.$ ), washed in $1 \times$ PBS and resuspended in RNAprotect (Qiagen).

Motility tests. Observation of straight-line motility was employed to ascertain the presence or absence of flagella in the AES-1 and NC isolates. Ten fields of view per isolate were examined by the hanging drop method, and phase-contrast microscopy for non-Brownian motion and $+/-$ scoring was used to classify isolates.

RNA extraction and purification. Cells were treated with RNAprotect (Qiagen) and total RNA was extracted using an RNeasy mini 
purification kit (Qiagen). RNA concentration was determined by measuring the absorbance at $260 \mathrm{~nm}$, with a minimum of $500 \mathrm{ng}$ RNA $\mu \mathrm{l}^{-1}$ required to proceed to cDNA synthesis. RNA quality and the presence of residual DNA were checked by formaldehyde/agarose gel electrophoresis (Ausubel et al., 2003).

cDNA synthesis, fragmentation and labelling. cDNA was synthesized, fragmented and labelled following the instructions of the Affymetrix GeneChip expression analysis technical manual. cDNA was purified using a MinElute PCR purification kit (Qiagen), fragmented with DNase I (Amersham Biosciences) and the fragments 3'-end-labelled using GeneChip DNA Labelling Reagent (Affymetrix). Fragmented DNA was quality checked (Bioanalyser 2100; Agilent) and hybridized to the $P$. aeruginosa genome array following the Affymetrix protocol. A 'test3' array (Affymetrix-100 housekeeping genes) was used to determine DNA suitability for the full array. Array conditions were as follows: hybridization was carried out at $50{ }^{\circ} \mathrm{C}$ for $16 \mathrm{~h}$, at 60 r.p.m.; washing was carried out using an Affymetrix Fluidics Station 450; and scanning was carried out using an Affymetrix GeneChip Scanner 3000 at $532 \mathrm{~nm}$ for excitation and $570 \mathrm{~nm}$ for emission. CEL and CHP files were generated using the scanner program GCOS.

Replicates for microarray analysis. The four AES-1 isolates and four NC isolates were treated as biological replicates in a two-group differential expression analysis. Two technical replicates (same isolate, same culture, same RNA extraction, different microarrays) of one AES-1 biofilm (isolate 1) and two planktonic NC isolates (isolates 6 and 7) were also analysed by microarray to assess technical variability. A comparison of fluorescence values for all genes showed no significant difference between the technical replicates.

Three isolates were analysed by microarray as biological replicates to assess biological variability at the level of culture (same isolate, different culture, different RNA extraction and different microarray): one planktonic isolate (isolate 4) and one biofilm-grown AES-1 isolate (isolate 3 ) were analysed by microarray in duplicate, and one planktonic NC isolate (isolate 8) was analysed in triplicate. Substitution of different biological (culture) replicates had little or no effect on the prediction of differentially expressed genes. Pair-wise comparisons of the data from the two planktonic AES- 1 replicates and the two biofilm AES-1 replicates gave $R^{2}$ values of 0.61 and 0.64 , respectively, whilst the three NC replicates gave $R^{2}$ values of $0.55,0.56$ and 0.59 , reflecting the inherent variability between isolates. The microarray data are available on the GEO (Gene Expression Omnibus) website at http://www.ncbi.nlm.nih.gov/projects/geo (GEO accession no. GSE6122).

Data analysis. Microarray data were analysed using BIOCONDUCTOR (Gentleman et al., 2004). Data normalization used the robust multiarray average method (Gautier et al., 2004; Irizarry et al., 2003) incorporating probe level background correction, quantile normalization (Bolstad et al., 2003) and linear extraction of a final expression measure for each gene per array. These expression measures were used to determine differential expression using the empirical Bayes method (Smyth, 2004). The false discovery rate method (Benjamini \& Hochberg, 1995) was controlled to reduce false positives. A positive B-statistic was used as a guide for statistically significant differential expression (Smyth, 2003). Data were combined with the latest information from the $P$. aeruginosa sequence annotation project (PseudoCAP) at http://www.pseudomonas.com.

Microarray validation. Array data were validated by quantitative SYBR Green PCR using a Rotor-Gene 6000 real-time amplification system (Corbett Life Sciences) and performed on cDNA synthesized from microarray RNA. Eight genes (exoT, $p v d A, l a s B, b d h A, a p r A$, prtB, PA0986 and P. aeruginosa PAK strain flaA) were chosen based on high differential expression, association with virulence and/or known function. Expression of the test genes was measured in biological duplicates, and ratios were calculated using the recA gene as endogenous control. Measurements were made under all conditions for all isolates. Oligonucleotide primers were designed using Primer Express (Applied Biosystems). Reverse transcription using $50 \mathrm{U}$ SuperScriptII reverse transcriptase (Invitrogen) and $1 \mu \mathrm{g}$ total RNA was carried out as recommended by the manufacturer (Invitrogen).

\section{Follow-up studies: PCR detection of non-expressing genes}

For PCR detection of selected genes showing no fluorescence in the arrays, a further 17 AES- 1 and $17 \mathrm{NC}$ isolates were chosen from our bank of $300 P$. aeruginosa isolates to reflect all adult age groups and both genders. The aim was to differentiate genes that were absent or extensively mutated from those that were present in the genome but not expressed. Thirteen genes showing no expression by microarray analysis (fluorescence absent) in all AES-1 or all NC isolates were chosen for PCR analysis to determine gene absence or mutation (see Table 2). Genes were chosen based on their putative virulence or infectivity characteristics.

\section{RESULTS AND DISCUSSION}

This study used PAO1 arrays to identify a core set of genes that were differentially expressed in the AES-1 strain compared with $\mathrm{NC}$ strains and revealed differences in biofilm-forming characteristics between AES-1 and NC strains.

\section{Biofilm formation}

Biofilms from all four AES-1 isolates exhibited significantly more surface coverage than $\mathrm{NC}$ and $\mathrm{PAO} 1$ biofilms at 24 and $48 \mathrm{~h}(P<0.01)$ and at $72 \mathrm{~h}(P<0.05)$ post-inoculation (Fig. 1a). AES-1 biofilms were also significantly thicker than NC and PAO1 biofilms at $72 \mathrm{~h}(P<0.05)$ (Fig. 1a). Representative PAO1, AES-1 and NC biofilms at all time points are shown for surface area (Fig. 1b). No observable difference in shape was apparent between the four AES-1 isolates. A common feature in all four AES-1 isolates was filament formation (Fig. 1b), though its contribution to increased surface coverage is unknown. The propensity of AES-1 to form larger biofilms than either PAO1 or NC isolates may influence this clonal strain's infectivity. Recent in vitro biofilm studies of LES strain B58 also showed that this clonal isolate produced more biofilm than PAO1 (Kukavica-Ibrulj et al., 2008).

\section{Transcriptome analyses}

Mean transcript expression levels were $89 \%$ for planktonically grown isolates and $85 \%$ for biofilm isolates. These values are comparable to other studies (Ochsner et al., 2002; Wagner et al., 2003). Initially, AES-1 and NC expression profiles from planktonic and biofilm-grown cultures were each compared with those for PAO1. Subsequently, comparisons were made between AES-1 and NC isolates. Table 1 shows the number of genes that were significantly differentially expressed between PAO1 and all AES-1 and NC isolates in planktonic and biofilm culture. 
(a)

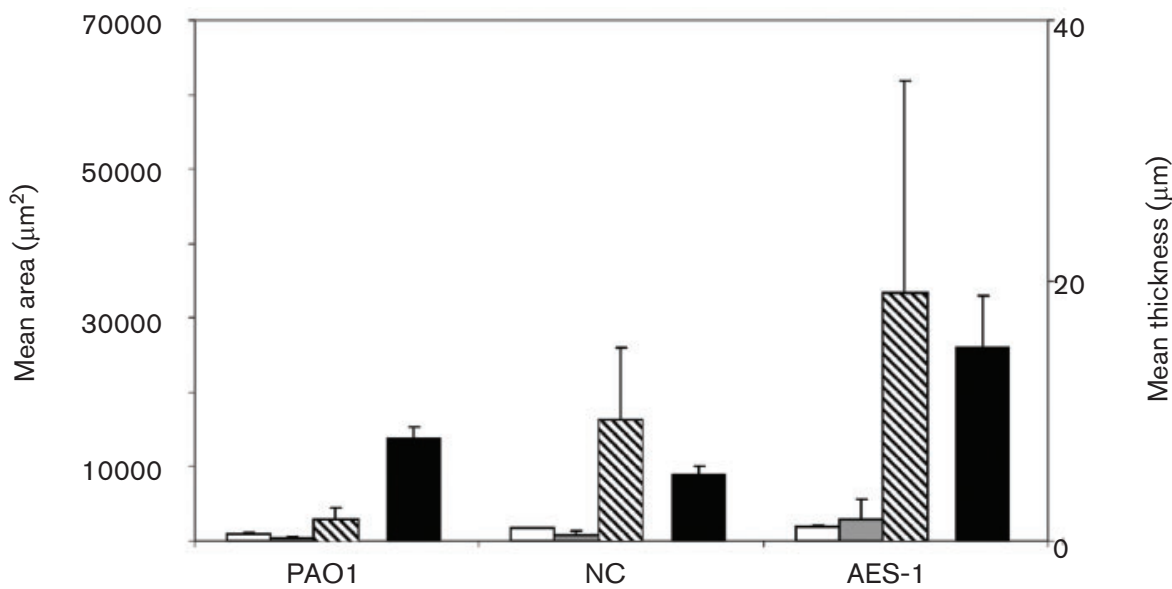

(b)
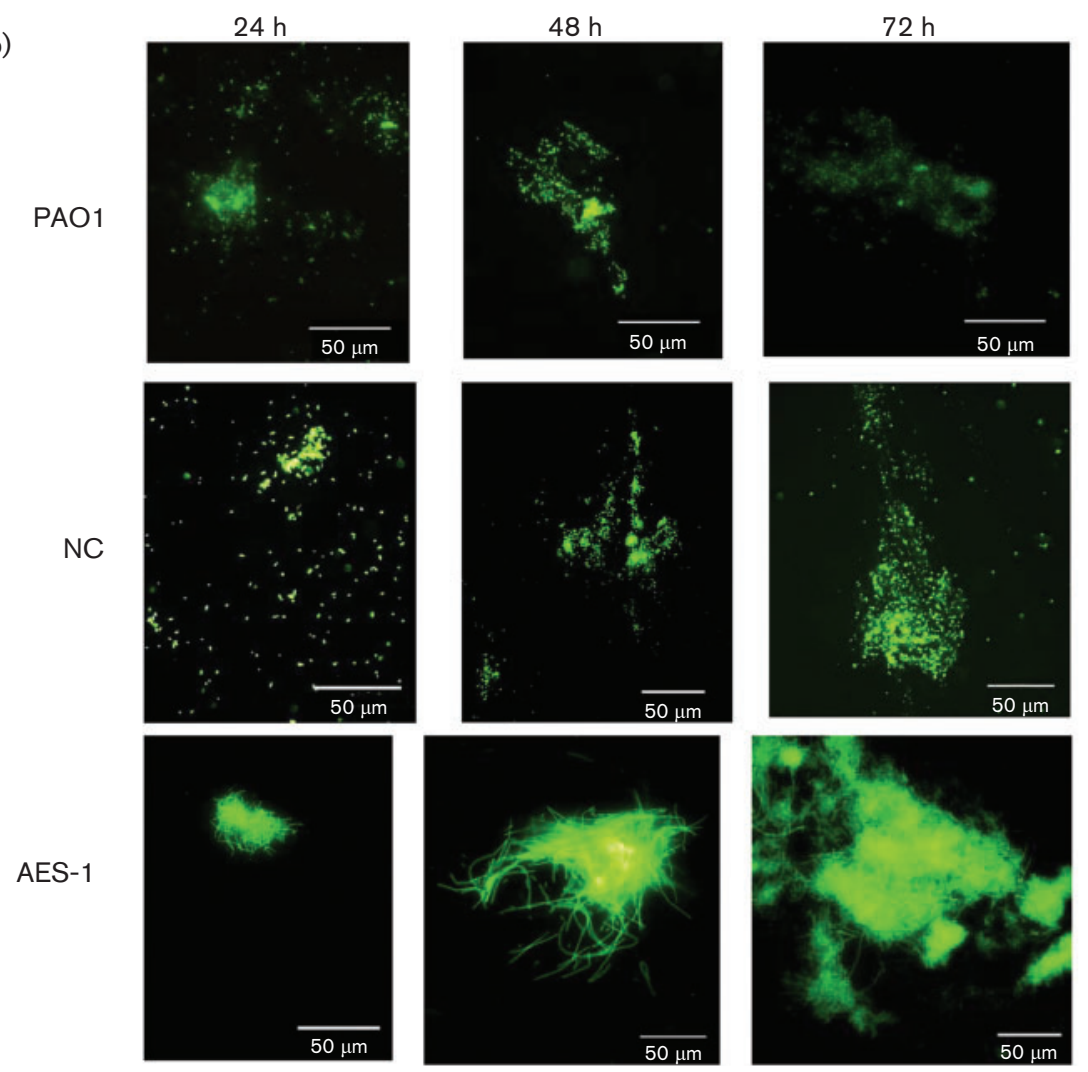

Fig. 1. (a) Comparison of mean biofilm areas for $P$. aeruginosa PAO1, AES-1 and NC isolates at $24 \mathrm{~h}$ (white bars), $48 \mathrm{~h}$ (grey bars) and $72 \mathrm{~h}$ (hatched bars). Each isolate was grown twice (biological replicate) in a Centers for Disease Control and Protection Bioreactor and individual rods removed at the specified times for Syto9 staining of cells and image acquisition. The areas of ten randomly selected biofilm images were measured for each replicate of each isolate $(n=20)$. The mean biofilm areas for each isolate at each time point and the mean biofilm thickness at $72 \mathrm{~h}$ (black bars) are shown (mean \pm SEM). AES-1 biofilm areas were significantly larger than those of $\mathrm{NC}$ isolates and PAO1 at 24 and $48 \mathrm{~h}(P<0.01)$. AES-1 biofilms were also significantly larger and thicker than NC isolates and PAO1 at $72 \mathrm{~h}(P<0.05)$. (b) Biofilm development of $P$. aeruginosa AES-1 (isolate 2), NC (isolate 7) and PAO1 (ATCC 15692) at 24, 48 and $72 \mathrm{~h}$ showing the difference in biofilm area in representative isolates. Biofilm images were selected from ten randomly chosen biofilms measured for size for each isolate. 
Table 1. Differential gene expression in AES-1, NC and PAO1

Only genes showing expression in all isolates and with a B statistic $>0$ are shown, with the exception of the bacteriophage genes PA0729 and PA0632-PA0639 (identified with an asterisk).

\begin{tabular}{|c|c|c|c|c|c|c|}
\hline Gene & $\begin{array}{l}\text { Planktonic } \\
\text { AES-1 vs } \\
\text { PAO1 }\end{array}$ & $\begin{array}{l}\text { Biofilm } \\
\text { AES-1 vs } \\
\text { PAO1 }\end{array}$ & $\begin{array}{c}\text { Planktonic } \\
\text { NC vs } \\
\text { PAO1 }\end{array}$ & $\begin{array}{l}\text { Biofilm NC } \\
\text { vs PAO1 }\end{array}$ & $\begin{array}{c}\text { Planktonic } \\
\text { AES-1 vs } \\
\text { NC }\end{array}$ & $\begin{array}{l}\text { Description } \\
\text { of protein }\end{array}$ \\
\hline \multicolumn{7}{|l|}{ Upregulated genes } \\
\hline PA0197 & & & & 2.9 & & Transport of small molecules \\
\hline PA0729 & $2.9^{*}$ & & & & & Bacteriophage Pf4 protein \\
\hline PA0979 & & 3.9 & & & & Related to phage/transposon/plasmid \\
\hline PA0986 & 4.7 & & & & 7.2 & Probable transposase \\
\hline PA1414 & & & 4.4 & & & Hypothetical protein \\
\hline PA1673 & & & 3.4 & & & Hypothetical protein \\
\hline PA2103 (moeB) & & & & & 3.4 & $\begin{array}{l}\text { Probable molybdopterin biosynthesis } \\
\text { protein MoeB }\end{array}$ \\
\hline \multicolumn{7}{|l|}{$\begin{array}{l}\text { Downregulated } \\
\text { genes }\end{array}$} \\
\hline PA0044 (exoT) & & -20.4 & & -17.9 & & Exoenzyme $\mathrm{T}$ \\
\hline PA0610 (prtN) & & & & -6.1 & & Transcriptional regulator PrtN \\
\hline PA0612 (prtB) & & -7.1 & & & -2.3 & DksA, DnaK suppressor protein \\
\hline PA0632-PA0639 & -3.4 to $-11.2^{\star}$ & & & & & Bacteriophage N15 assembly proteins \\
\hline PA1244 & & & -9.6 & & & Hypothetical protein \\
\hline PA1245 & & & -10.0 & & & Hypothetical protein \\
\hline PA1246 (aprF) & & & -5.4 & & & Alkaline protease transport protein \\
\hline PA1247 (aprE) & & & -4.1 & & & Alkaline protease transport protein \\
\hline $\operatorname{PA} 1249(a p r A)$ & & & -4.7 & & & Alkaline protease \\
\hline PA1713 (exsA) & & -14.4 & & & & Transcriptional regulator ExsA \\
\hline PA1714 & & -15.1 & & & & Hypothetical protein \\
\hline PA1939 & & -5.2 & & & & Hypothetical protein \\
\hline PA1947 (rbsA) & & -6.3 & & -5.2 & & Ribose transport protein RbsA \\
\hline PA1959 (bacA) & & & & -3.4 & & Bacitracin resistance protein \\
\hline PA2003 (bdhA) & -5.1 & & & & & 3-Hydroxybutyrate dehydrogenase \\
\hline PA2008 (fahA) & -4.6 & & & & & Fumarylacetoacetase \\
\hline PA2009 $(h m g A)$ & -4.9 & & & & & Homogentisate 1,2-dioxygenase \\
\hline $\operatorname{PA} 2386(p v d A)$ & -6.9 & & & & & L-Ornithine N5 oxygenase \\
\hline PA2460 & & & -3.2 & & & Hypothetical protein \\
\hline PA2482 & & -3.1 & & -2.9 & & Probable cytochrome $c$ \\
\hline PA2565 & -19.9 & & & & & Hypothetical protein \\
\hline PA3371 & & -4.3 & & & & Hypothetical protein \\
\hline PA3488 & & & -6.6 & & & Hypothetical protein \\
\hline PA3528 $(r n t)$ & & & & & -2.3 & RNase $\mathrm{T}$ \\
\hline PA3841 (exoS) & & -20.1 & & & & Exoenzyme S \\
\hline PA4443 & -3.5 & & & & & ATP sulfurylase small subunit \\
\hline PA4918 & & -4.7 & & -6.3 & & Hypothetical protein \\
\hline PA5167 & & -3.2 & & & & Probable c4-dicarboxylate-binding protein \\
\hline PA5374 (betI) & & & & -6.2 & & Transcriptional regulator BetI \\
\hline Pae tRNA $(\mathrm{Met})$ & & -17.30 & & -11.3 & & $\begin{array}{l}\text { tRNA Methionine, 5242026-5242102(+) } \\
\text { strand }\end{array}$ \\
\hline \multicolumn{7}{|l|}{$\begin{array}{l}\text { Non-PAO1 genes } \\
\text { expressed in AES-1 }\end{array}$} \\
\hline Pae_M57501cdsg & + & + & & & & Flagellin-encoding gene $f l a A$ strain PAK \\
\hline Pae_AF035937cds6 & + & + & & & & WbpQ ( $P$. aeruginosa IATS06) \\
\hline Pae_AF035937cds8 & + & + & & & & WbpR ( $P$. aeruginosa IATS06) \\
\hline Pae_AF035937cds11 & + & + & & & & WbpU ( $P$. aeruginosa IATS06) \\
\hline Pae_AF035937cds12 & + & + & & & & $\mathrm{WbpV}$ ( $P$. aeruginosa IATS06) \\
\hline Pae_L81176cds3 & & + & & & & Flagellar cap protein FliD strain PAK \\
\hline Pae orfG & + & + & & & & $\begin{array}{l}\text { Putative acetyl transferase from glycosyla- } \\
\text { tion island genes in strain PAK }\end{array}$ \\
\hline
\end{tabular}


Table 1. cont.

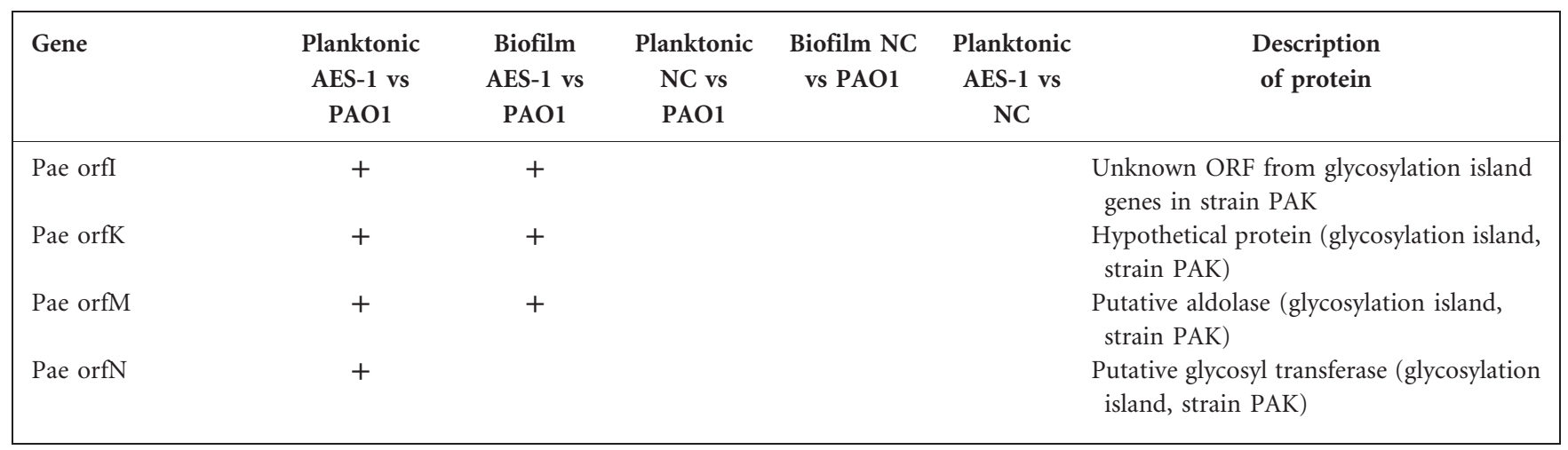

Table 2. Oligonucleotide primers used in PCR amplification of selected genes

\begin{tabular}{|c|c|c|c|c|}
\hline Gene/strain & Primer $\left(5^{\prime} \rightarrow 3^{\prime}\right)$ & Product (bp) & AES-1 & NC \\
\hline PA0632-PA0633 & $\begin{array}{l}\text { CGGTACAACGTAGTCATGCTT } \\
\text { GTAGCGACCAGCGTGTTG }\end{array}$ & 666 & Absent & Present \\
\hline PA0636-PA0637 & $\begin{array}{l}\text { CTGTGCCACTGGTGCATCAC } \\
\text { GGATAGTCCGGAAGCTCCAAAC }\end{array}$ & 662 & Absent & Present \\
\hline PA0729-PA0730 & $\begin{array}{l}\text { GTTACCCAGTCAGCCAGCAG } \\
\text { CCTGGTCAACGAAACCATCG }\end{array}$ & 775 & Present & Absent \\
\hline PA0724 & $\begin{array}{l}\text { GAAGTTTGCGAGCCTGATTC } \\
\text { CGGTGGAGCAGTTCTCTTTC }\end{array}$ & 926 & Absent & Absent \\
\hline PA2032 & $\begin{array}{l}\text { CGAAGTCCGGCTATTTCGT } \\
\text { ACCCAGTCGATCATCAGGTC }\end{array}$ & 970 & Present & Present in three isolates \\
\hline fliC (PA1092) & $\begin{array}{l}\text { CAACGGCTCCAACAGCGA } \\
\text { CTGCGAAGCCTGGGTGC }\end{array}$ & 822 & Absent & Present in isolates 5 and 6 \\
\hline flaA (strain PAK): primer set 1 & $\begin{array}{l}\text { CAACGGCTCCAACAGCGA } \\
\text { CCGGTGTCAGCGATGACAA }\end{array}$ & 506 & Absent $^{*}$ & Present in isolates 7 and 8 \\
\hline flaA (strain PAK): primer set 2 & $\begin{array}{l}\text { GCCAACGACGGTATCTCCC } \\
\text { GCAGCAGGCTCAGAACCG }\end{array}$ & 978 & Present & Present in isolates 7 and 8 \\
\hline fliD (PA1094) & $\begin{array}{l}\text { GACAACGTCAAGAAGTTCGTC } \\
\text { CCTTGTCGAGCTTCTTCTTCTC }\end{array}$ & 265 & Absent & Present in isolates 5 and 6 \\
\hline fpvA (PA2398) & $\begin{array}{l}\text { GTCACCCGCCAGAACATGGA } \\
\text { CAGCTCGTGCTCGCGAC }\end{array}$ & 909 & Present & Present \\
\hline
\end{tabular}

${ }^{*}$ Not detected due to mutations in reverse primer-binding region. These were detected by sequencing the larger PCR product (978 bp) amplified using primer set 2 .

Overall features

Overall, the proportion of genes showing differential expression during biofilm growth for both AES-1 and NC isolates was $\sim 0.3 \%$. This is low compared with other studies (Waite et al., 2005; Whiteley et al., 2001), where it ranged between 1 and $20 \%$, and probably reflects the inherent variability of the NC isolates as well as differences in methods used to generate biofilms and varying harvest time points. However, the general trend seems to be a decrease in the number of differentially expressed genes compared with planktonic growth, as the biofilm matures (Davies et al., 1998; De Kievit et al., 2001; Sauer et al., 2002; Whiteley et al., 2001). The most prominent gene groups identified in the various comparisons are discussed below. 
Bacteriophage-related genes

The bacteriophage-related genes PA0729 and PA0986 were upregulated 2.9-fold and 4.7-fold, respectively, whilst the bacteriophage-related cluster PA0632-PA0639 was downregulated 3.4-fold to 11.2-fold in all AES-1 isolates compared with NC (Table 1). The PA0729 gene was subsequently found to be absent by PCR in all NC isolates, whilst PA0632-PA0639 was absent in all AES-1 isolates. PA0729 is part of the integrated Pf4 prophage in PAO1, and the PA0729 gene product probably influences $P$. aeruginosa biofilm development (Hentzer et al., 2004; Kim et al., 2003; Webb et al., 2004; Whiteley et al., 2001). This may help explain the enhanced biofilm-forming capacity of AES-1 compared with NC strains, which produced significantly smaller biofilms in this study and do not have the PA0729 gene. PA0729 and the adjacent gene PA0730 together have $79 \%$ nucleotide sequence identity with the 'prevent host death' ( $p h d$ ) toxin-antitoxin-encoding genes of Pseudomonas syringae (GenBank accession no. NP_790091.1) (Buell et al., 2003; Webb et al., 2004). Toxin-antitoxin genes, often located on mobile cassettes, may aid in phage retention through elimination of nonphage-containing cells (Lewis et al., 2005). They are probably important in stress-resistant and persistor phenotypes, where induction of cellular stress responses by the toxin-antitoxin locus renders cells more resistant to antimicrobials (Pandey \& Gerdes, 2005). The gene cluster PA0632-PA0639 has high nucleotide identity to the tail proteins of bacteriophage N15 (Ravin et al., 2000). N15 has been identified as having a functional stabilization system, which acts on the toxin-antitoxin principle described above (Dziewit et al., 2007).

In order to further explore putative associations, we felt it was important to establish the prevalence of these genes in a large number of AES-1 and NC isolates. This may also establish them as potential markers of AES-1 infection. The prevalence of genes PA0729 and PA0632-PA0639 was analysed in 21 AES-1 and $21 \mathrm{NC}$ isolates by PCR, which revealed that PA0729 was present in all 21 AES-1 isolates compared with only $6 \mathrm{NC}$ isolates $(P<0.001)$, whilst PA0632-PA0639 was amplified in $13 \mathrm{NC}$ isolates compared with 3 AES-1 isolates $(P<0.001)$. Whilst several PCR primer sets (Table 2) were used to conclude the absence/presence of genes, there is a small possibility that they all failed to amplify a product due to mutations in the target regions of the templates. Confirmation of the sequence was obtained by sequencing of the PCR products. These findings demonstrated a link between AES-1 and the LES clonal strains LES400 and LES431, which also lack the genes PA0632-PA0648 whilst retaining PA0729 (Salunkhe et al., 2005). Another Pf4 gene, PA0724, was not expressed in any isolates (AES-1 or NC) and PCR failed to amplify it. This is interesting as it indicates that the presence or expression of other Pf4 genes is not essential to PA0729 expression.

Whilst PA0729 was expressed in PAO1, it is worth noting that the mean expression of PA0729 across the four planktonic AES-1 was threefold higher than in planktonic
PAO1. In mature $(72 \mathrm{~h})$ biofilms, the mean PA0729 expression in AES-1 was still approximately 1.5 -fold higher than PAO1. Subsequent microarray analysis of two of the six NC isolates containing the PA0729 gene (from PCR analysis) showed no and very low expression, respectively. Thus, the higher expression of PA0729 in AES-1 compared with PAO1 and NC strains indicates that planktonic AES-1 may be primed for enhanced biofilm formation.

Another differentially expressed bacteriophage gene, PA0986, was upregulated compared with both PAO1 and $\mathrm{NC}$ isolates. PA0986 has $95 \%$ nucleotide similarity to IS407, a geneactivating transposase of Burkholderia cenocepacia. Virulent, multi-resistant epidemic strains of B. cenocepacia are highly pathogenic to CF patients. Studies by Mack \& Titball (1998) showed that two strains of $B$. cenocepacia that contained IS407 (C1576 and J2315) have been associated with epidemic outbreaks, whilst the avirulent E27 and E82 strains did not contain IS407, suggesting an association between this transposase and virulence in B. cenocepacia.

\section{Motility genes}

The AES-1 isolates were found to express the flaA flagellinencoding gene originally identified in $P$. aeruginosa PAK (Pae M57501cdsg) (Arora et al., 2001), rather than the PAO1 flagellin-encoding gene fliC. Confirmation was obtained by PCR (Table 2) and sequencing of flagellin genes from the eight AES-1 and NC isolates, which demonstrated that the AES-1 flagellin-encoding gene was approximately $95 \%$ identical to flaA (PAK), with the remaining $5 \%$ comprising two insertions totalling $21 \mathrm{bp}$ and 40 single-base differences (including insertions/deletions and base switches). Sequencing also showed that the two NC isolates contained flaA whilst the other two contained fliC.

Expression studies and PCR confirmation also showed that AES-1 isolates had the PAK fliD (Pae L81176cds3), not the PAO1 variant, fliD (PA1094). The PAO1 flgK (PA1086) was also absent, but PAO1 flgL (PA1087) was found to be present by expression and PCR. This degree of genetic switching/ variation within flagellar genes has been reported for other bacteria, and has been shown to affect flagellar shape and thus motility (Manos et al., 2004). In qualitative tests of $P$. aeruginosa isolate motility, we found that planktonic AES-1 isolates displayed greater motility than NC isolates under the microscope (data not shown). With respect to $f l i D$, a study by Scharfman et al. (2001) found that whether a strain expresses the PAO1 or the PAK FliD protein can affect its ability to bind to recognition sites on carbohydrate epitopes of human respiratory mucins, and concluded that FliD specificity is required for mucus colonization.

The two PAK genes fliD and flaA were also highly expressed in AES-1 biofilms. Studies indicate that motility may be significant in the early biofilm stage for some isolates (Head \& Yu, 2004; Klausen et al., 2003). Overall, these results suggested a different genetic response to biofilm formation between NC and AES- 1 isolates that may provide clues to AES-1 infectivity. 
Virulence and quorum-sensing (OS)-related genes

One interesting finding was the low number of differentially expressed virulence and QS-related genes in all of the CF isolates analysed by microarray compared with PAO1. A comparison of AES-1 results with those from LES400 and LES431 (Salunkhe et al., 2005) showed a similar lack of differentially expressed virulence factors and QS-related genes. Exceptions included downregulation of the QSregulated genes fahA (PA2008) and hmgA (PA2009), seen in both AES-1 and LES. The lack of differentially expressed virulence genes in both the AES-1 and LES isolates probably reflects the fact that they were isolated from chronically infected patients. It could also be that both the AES-1 and LES clonal strains have strain-specific virulence or QS-related genes that are not present on the PAO1 array.

Some virulence-related genes were downregulated in NC but not AES-1 isolates when compared with PAO1. These included $a p r F$ (PA1246) and aprE (PA1247) - genes encoding the $\mathrm{ABC}$ transport system that exports alkaline protease - and the protease itself, aprA (PA1249). Alkaline protease is a QS-regulated exoenzyme with optimal activity at alkaline $\mathrm{pH}$ and is an important $P$. aeruginosa virulence factor necessary for adaptation to the CF lung (Kim et al., 2006). Its downregulation in NC may be an indicator of reduced virulence in these NC isolates, although the small number of isolates analysed by microarray does not allow a more detailed analysis. Two genes encoding hypothetical proteins adjacent to the alkaline protease cluster (PA1244 and PA1245) were also significantly downregulated, suggesting a putative link to the alkaline protease cluster. Other virulence genes such as exoT (PA0044) were downregulated in both AES-1 and NC isolates, and this downregulation is probably a consequence of chronic infection.

The virulence factor pyoverdine gene, $p v d A$ (PA2386), was downregulated in AES-1. Pyoverdine aids growth in the iron-deprived environment of the CF lung (Lamont et al., 2002) and its downregulation suggests that AES- 1 may possess other iron-acquisition genes. Interestingly, the pyoverdine receptor gene, fpvA (PA2398), was not expressed in any AES-1 isolates. Deletion of $f p v A$ in $P$. aeruginosa has been shown to reduce pyoverdine production (Shen et al., 2002). PCR (Table 2) and sequencing of $f p v A$ were conducted, and showed that all AES-1 and NC isolates had the intact $f p v A$ gene.

Differential gene expression in the switch from planktonic to biofilm growth

Not surprisingly, there was an overall trend for both AES-1 and NC isolates to undergo downregulation of gene expression in the transition from planktonic to biofilm growth (Table 3), although interestingly there were only two genes, the amino acid transporter ammonium aspartate lyase-encoding aspA (PA5429) and PA2937 (encoding a hypothetical protein), that were differentially expressed in common by both groups. Few QS or QSregulated genes were differentially expressed in either the

Table 3. Differential gene expression during the switch from planktonic to biofilm growth

Genes shown in bold were differentially expressed in both AES-1 and NC.

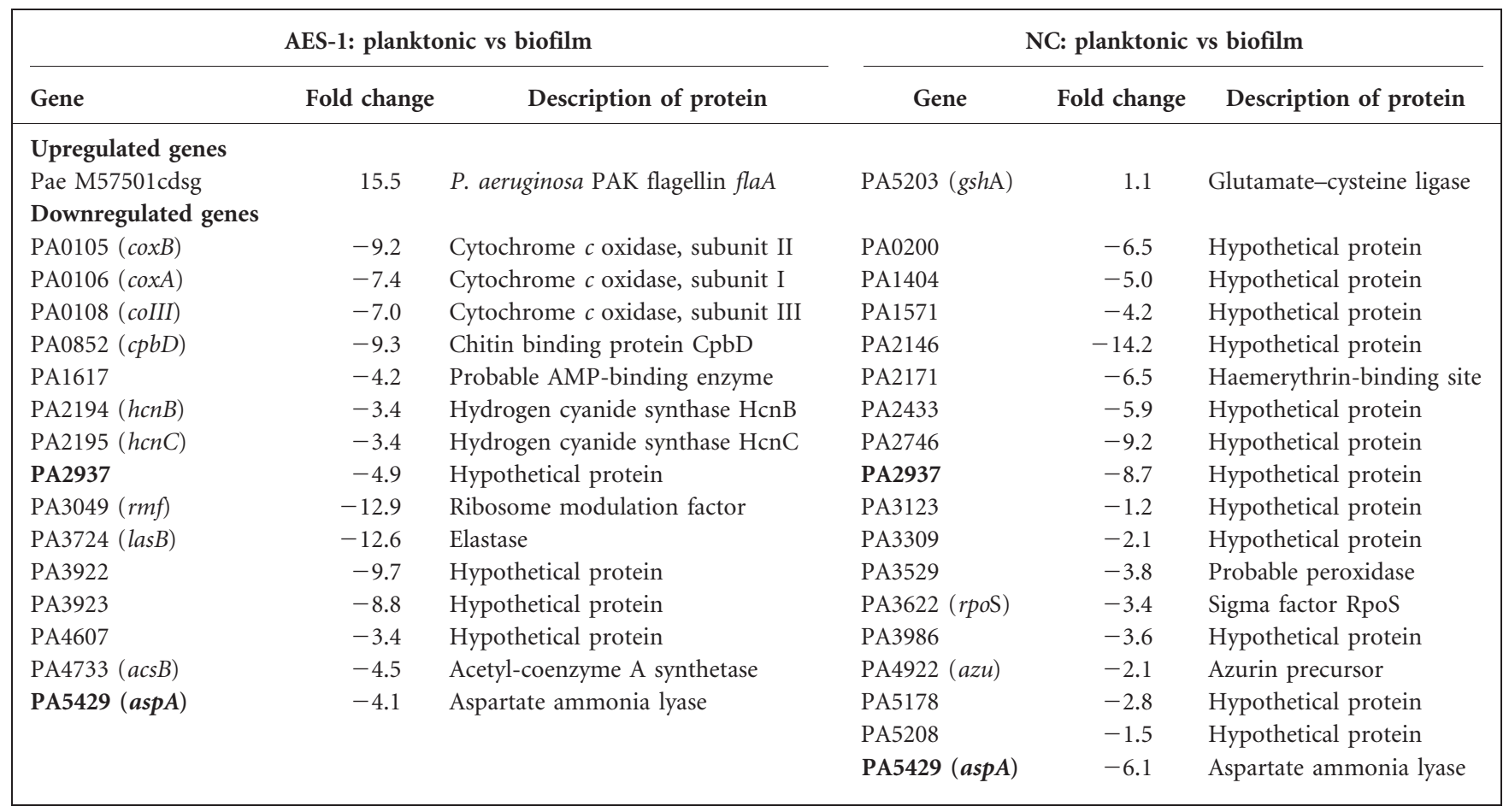


AES-1 or NC transition to biofilm. Other studies have also found this to be the case in PAO1, where biofilm transcriptomics and proteomics studies have shown a lower level of downregulation of QS and anaerobic respiration genes (Nouwens et al., 2003; Schuster et al., 2003; Wagner et al., 2003).

Genes involved in aerobic respiration, including $\operatorname{cox} A$, $\operatorname{cox} B$, collI, $h c n B$ and $h c n C$, were heavily downregulated (by a mean of about eightfold). These genes were not downregulated in the $\mathrm{NC}$ or PAO1 biofilms, suggesting that AES-1 isolates may achieve an anaerobic microenvironment more rapidly than $\mathrm{NC}$ isolates or PAO1 as they rapidly formed larger biofilms. Other highly downregulated genes included those encoding the QS-regulated virulence factors elastase lasB (PA3724) and chitin-binding protein $c p b D$ (PA0852), the ribosome modulation factor rmf (PA3049), PA3922 [homologous to the poly(3hydoxyoctanoic acid) depolymerase of Pseudomonas fluorescens GK13; Schirmer \& Jendrossek, 1994] and PA3923 (putative type $\mathrm{V}$ secretory pathway adhesin AidA of $P$. aeruginosa MA; Lewis et al., 2005). Downregulation of virulence genes suggests that biofilms of chronically infecting AES-1 isolates may be better adapted to persistence. The flagellin-encoding gene (flaA, P. aeruginosa strain PAK) was the only upregulated gene in AES-1 biofilms (Table 3), indicating that AES-1 biofilm cells may retain the ability to disperse more easily.
In NC biofilms (Table 3), three downregulated genes encoded proteins of known function: rpoS (PA3622), azu (PA4922) and aspA (PA5429). Downregulation of rpoS, which encodes the sigma factor responsible for activating stress response mechanisms (Suh et al., 1999), occurred only in NC biofilms. As seen in this study, NC biofilms are significantly smaller than those of AES-1. It is likely that activation of stress response genes is more critical in larger, more complex biofilms such as those formed by AES- 1 .

Mature AES-1 and NC biofilms show no gene expression differences

No genes were differentially expressed between AES- 1 and $\mathrm{NC}$ isolates in our comparative analysis of gene expression in biofilms. This is not unexpected as it is likely that gene expression differences occur at the initial stage of biofilm formation, rather than at the mature biofilm stage, giving AES-1 biofilms an advantage of growing more rapidly. This was supported by the biofilm images (Fig. 1b), which showed a slower rate of growth in NC compared with AES1 isolates at all three time points.

\section{Microarray validation}

The microarray expression ratios of the eight selected genes (see Methods) correlated with the mean quantitative RTPCR ratios obtained (correlation coefficient $R^{2}=0.7914$ ).

Table 4. Comparison of microarray and quantitative RT-PCR fold values

\begin{tabular}{|c|c|c|c|c|c|}
\hline \multirow[t]{2}{*}{ Comparison (isolate no.) } & \multirow[t]{2}{*}{ Growth condition } & \multirow[t]{2}{*}{ Gene } & \multirow[t]{2}{*}{ Description of protein } & \multicolumn{2}{|c|}{ Fold difference } \\
\hline & & & & Micro-array & Mean qRT-PCR \\
\hline PAO1 vs AES-1 (1) & PL & $b d h A$ & 3-Hydroxybutyrate dehydrogenase & -5.1 & -18.9 \\
\hline PAO1 vs AES-1 (3) & PL & $b d h A$ & 3-Hydroxybutyrate dehydrogenase & -13.9 & -17.0 \\
\hline PAO1 vs AES-1 (1) & PL & $p v d A$ & L-Ornithine N5 oxygenase & -4.8 & -23.1 \\
\hline PAO1 vs AES-1 (3) & PL & $p v d A$ & L-Ornithine N5 oxygenase & -14.8 & -19.4 \\
\hline PAO1 vs AES-1 (1) & PL & PA0986 & Probable transposase & 8.4 & 11.3 \\
\hline PAO1 vs AES-1 (3) & PL & PA0986 & Probable transposase & 2.9 & 2.5 \\
\hline PAO1 vs AES-1 (1) & $\mathrm{BIO}$ & $p v d A$ & L-Ornithine N5 oxygenase & 5.1 & 14.5 \\
\hline PAO1 vs AES-1 (3) & $\mathrm{BIO}$ & $p v d A$ & L-Ornithine N5 oxygenase & 1.7 & 3.1 \\
\hline PAO1 vs AES-1 (1) & $\mathrm{BIO}$ & $\operatorname{prtB}$ & DksA, DnaK suppressor protein & -5.2 & -2.3 \\
\hline PAO1 vs AES-1 (3) & $\mathrm{BIO}$ & $\operatorname{prtB}$ & DksA, DnaK suppressor protein & -11.2 & -17.6 \\
\hline PAO1 vs AES-1(1) & PL vs $\mathrm{BIO}$ & exoT & Exoenzyme $\mathrm{T}$ & -8.0 & -10.8 \\
\hline AES-1 vs AES-1 (1) & $\mathrm{PL}$ vs $\mathrm{BIO}$ & $p v d A$ & L-Ornithine N5 oxygenase & -5.9 & -7.2 \\
\hline AES-1 vs AES-1 (1) & PL vs $\mathrm{BIO}$ & $b d h A$ & 3-Hydroxybutyrate dehydrogenase & -3.7 & -3.0 \\
\hline AES-1 vs AES-1 (1) & PL vs $\mathrm{BIO}$ & $\operatorname{las} B$ & Elastase & -10.6 & -12.8 \\
\hline AES-1 vs AES-1(3) & $\mathrm{PL}$ vs $\mathrm{BIO}$ & las $B$ & Elastase & -44.7 & -39.4 \\
\hline AES-1 vs AES-1 (1) & PL vs $\mathrm{BIO}$ & flaA & Flagellin gene $P$. aeruginosa PAK & 6.5 & 12.3 \\
\hline AES-1 vs AES-1 (3) & $\mathrm{PL}$ vs $\mathrm{BIO}$ & $f l a A$ & Flagellin gene $P$. aeruginosa PAK & 8.8 & 14.1 \\
\hline PAO1 vs NC (5) & $\mathrm{PL}$ & aprA & Alkaline metalloproteinase precursor & -6.9 & -8.2 \\
\hline PAO1 vs NC (7) & PL & aprA & Alkaline metalloproteinase precursor & -4.9 & -7.0 \\
\hline PAO1 vs NC (7) & $\mathrm{BIO}$ & exoT & Exoenzyme $\mathrm{T}$ & -18.3 & -21.4 \\
\hline AES-1 (3) vs NC (5) & PL & prtB & DksA, DnaK suppressor protein & -4.9 & -7.7 \\
\hline AES-1 (3) vs NC (7) & PL & $\operatorname{prtB}$ & DksA, DnaK suppressor protein & -5.4 & -7.1 \\
\hline
\end{tabular}


All genes evaluated showed either upregulation or downregulation consistent with the microarray results (Table 4). Large variations in fold difference between microarray and RT-PCR were observed in two genes only, $p v d A$ and $b d h A$, in planktonic AES-1 versus PAO1.

\section{Genetic comparison of MA and AES-1}

We attempted to amplify putative transmissibility markers identified in the MA strain (Lewis et al., 2005) with the aim of identifying common markers of transmissibility between AES- 1 and MA. PCR of two of the five gene island markers identified in MA (MA18 and MA21; Lewis et al., 2005) failed to amplify either of the expected products in any AES-1 and NC isolates. Additionally, no MA gene island was found in AES-1 using primers modelled on sequences adjacent to its insertion point in MA (PA1013 and PA1014; data not shown). PCR of two genes highly conserved in MA (PA0724 and PA2032; Table 2) showed that PA0724 was absent in all AES-1 and NC isolates, whilst PA2032 was absent in one AES-1 but present in three of four NC isolates. The results suggested that these genes are not suitable as transmissibility markers in AES-1 as significant differences exist between the two clonal strains within these gene regions.

\section{Conclusions}

In summary, this study extends our understanding of the properties of both clonal and NC P. aeruginosa in the chronically infected CF lung. The clonal strain AES-1 shares a number of genetic characteristics with the LES and MA strains, as well as differences, and has a differentialexpression profile distinct from that of NC isolates. AES-1 also expressed the Pf4 bacteriophage gene PA0729, which may play a role in its enhanced biofilm formation compared with NC isolates. No particular set of differentially expressed genes in AES-1 could definitively be ascribed a role in its infectivity, thus increasing the likelihood that infectivity is multi-factorial. However the data from biofilm growth as well as gene expression suggest a need for follow-up studies to confirm the role of candidate motility and respiration genes in enhanced biofilm formation and increased infectivity. Our findings also need validation in clonal isolates from newly acquired infections where transmissibility determinants are intact. The study was also limited by the fact that we were unable to investigate gene expression of novel AES-1specific genes. As $P$. aeruginosa is capable of considerable genetic exchange, it is highly likely that there are AES-1 genes not present in the PAO1 genome that contribute to AES-1 transmissibility.

\section{ACKNOWLEDGEMENTS}

We are deeply indebted to Dr Mark Elkins and Carmel Moriarty of the Cystic Fibrosis Centre, Respiratory Investigation Unit, Royal Prince Alfred Hospital, for the collection of patient specimens and collation of clinical test results. We also wish to thank Professor Alex
Bishop of the Liver Transplantation Unit, Department of Pathology, University of Sydney, Australia, for his assistance in conducting and analysing the quantitative real-time PCR. This work was supported by a University of Sydney Sesqui grant (2004 - K9424 U1078).

\section{REFERENCES}

Al-Aloul, M., Crawley, J., Winstanley, C., Hart, C. A., Ledson, M. J. \& Walshaw, M. J. (2004). Increased morbidity associated with chronic infection by an epidemic Pseudomonas aeruginosa strain in CF patients. Thorax 59, 334-336.

Alvarez-Ortega, C. \& Harwood, C. S. (2007). Responses of Pseudomonas aeruginosa to low oxygen indicate that growth in the cystic fibrosis lung is by aerobic respiration. Mol Microbiol 65, 153-165.

Anthony, M., Rose, B., Pegler, M. B., Elkins, M., Service, H., Thamotharampillai, K., Watson, J., Robinson, M., Bye, P. \& other authors (2002). Genetic analysis of Pseudomonas aeruginosa isolates from the sputa of Australian adult cystic fibrosis patients. J Clin Microbiol 40, 2772-2778.

Armstrong, D. S., Nixon, G. M., Carzino, R., Bigham, A., Carlin, J. B., Robins-Browne, R. M. \& Grimwood, K. (2002). Detection of a widespread clone of Pseudomonas aeruginosa in a pediatric cystic fibrosis clinic. Am J Respir Crit Care Med 166, 983-987.

Armstrong, D., Bell, S., Robinson, M., Bye, P., Rose, B., Harbour, C., Lee, C., Service, H., Nissen, M. \& other authors (2003). Evidence for spread of a clonal strain of Pseudomonas aeruginosa among cystic fibrosis clinics. J Clin Microbiol 41, 2266-2267.

Arora, S. K., Bangera, M., Lory, S. \& Ramphal, R. (2001). A genomic island in Pseudomonas aeruginosa carries the determinants of flagellin glycosylation. Proc Natl Acad Sci U S A 98, 9342-9347.

Ausubel, F. M., Brent, R., Kingston, R. E., Moore, D. D., Seidman, J. G., Smith, J. A. \& Struhl, K. (2003). Current Protocols in Molecular Biology, 3rd edn. New York: John Wiley \& Sons.

Benjamini, Y. \& Hochberg, Y. (1995). Controlling the false discovery rate: a practical and powerful approach to multiple testing. $J R$ Stat Soc Ser B Methodological 57, 289-300.

Bolstad, B. M., Irizarry, R. A., Astrand, M. \& Speed, T. P. (2003). A comparison of normalization methods for high density oligonucleotide array data based on variance and bias. Bioinformatics 19, 185-193.

Brockhurst, M. A., Buckling, A. \& Rainey, P. B. (2005). The effect of a bacteriophage on diversification of the opportunistic bacterial pathogen, Pseudomonas aeruginosa. Proc Biol Sci 272, 1385-1391.

Buell, C. R., Joardar, V., Lindeberg, M., Selengut, J., Paulsen, I. T., Gwinn, M. L., Dodson, R. J., Deboy, R. T., Durkin, A. S. \& other authors (2003). The complete genome sequence of the Arabidopsis and tomato pathogen Pseudomonas syringae pv. tomato DC3000. Proc Natl Acad Sci U S A 100, 10181-10186.

Davies, D. G., Parsek, M. R., Pearson, J. P., Iglewski, B. H., Costerton, J. W. \& Greenberg, E. P. (1998). The involvement of cell-to-cell signals in the development of a bacterial biofilm. Science 280, 295-298.

De Kievit, T. R., Gillis, R., Marx, S., Brown, C. \& Iglewski, B. H. (2001). Quorum-sensing genes in Pseudomonas aeruginosa biofilms: their role and expression patterns. Appl Environ Microbiol 67, 1865-1873.

Drenkard, E. \& Ausubel, F. M. (2002). Pseudomonas biofilm formation and antibiotic resistance are linked to phenotypic variation. Nature 416, 740-743.

Dziewit, L., Jazurek, M., Drewniak, L., Baj, J. \& Bartosik, D. (2007). The SXT conjugative element and linear prophage N15 encode toxinantitoxin-stabilizing systems homologous to the tad-ata module of the Paracoccus aminophilus plasmid pAMI2. J Bacteriol 189, 1983-1997. 
Finnan, S., Morrissey, J. P., O’Gara, F. \& Boyd, E. F. (2004). Genome diversity of Pseudomonas aeruginosa isolates from cystic fibrosis patients and the hospital environment. J Clin Microbiol 42, 5783-5792.

Gautier, L., Cope, L., Bolstad, B. M. \& Irizarry, R. A. (2004). affy analysis of Affymetrix GeneChip data at the probe level. Bioinformatics 20, 307-315.

Gentleman, R. C., Carey, V. J., Bates, D. M., Bolstad, B., Dettling, M., Dudoit, S., Ellis, B., Gautier, L., Ge, Y. \& other authors (2004). Bioconductor: open software development for computational biology and bioinformatics. Genome Biol 5, R80.

Head, N. E. \& Yu, H. (2004). Cross-sectional analysis of clinical and environmental isolates of Pseudomonas aeruginosa: biofilm formation, virulence, and genome diversity. Infect Immun 72, 133-144.

Hentzer, M., Givskov, M. \& Eberl, L. (2004). Quorum sensing in biofilms: gossip in slime city. In Microbial Biofilms, pp. 118-140. Edited by M. Ghannoum \& G. A. O'Toole. Washington, DC: American Society for Microbiology.

Hentzer, M., Eberl, L. \& Givskov, M. (2005). Transcriptome analysis of Pseudomonas aeruginosa biofilm development: anaerobic respiration and iron limitation. Biofilms 2, 37-61.

Irizarry, R. A., Hobbs, B., Collin, F., Beazer-Barclay, Y. D., Antonellis, K. J., Scherf, U. \& Speed, T. P. (2003). Exploration, normalization, and summaries of high density oligonucleotide array probe level data. Biostatistics 4, 249-264.

Kim, S.-H., Lee, K.-B., Lee, J.-S. \& Cho, Y.-H. (2003). Genome diversification by phage-derived genomic islands in Pseudomonas aeruginosa. J Microbiol Biotechnol 13, 783-788.

Kim, S. J., Park, R. Y., Kang, S. M., Choi, M. H., Kim, C. M. \& Shin, S. H. (2006). Pseudomonas aeruginosa alkaline protease can facilitate siderophore-mediated iron-uptake via the proteolytic cleavage of transferrins. Biol Pharm Bull 29, 2295-2300.

Klausen, M., Heydorn, A., Ragas, P., Lambertsen, L., AaesJorgensen, A., Molin, S. \& Tolker-Nielsen, T. (2003). Biofilm formation by Pseudomonas aeruginosa wild type, flagella and type IV pili mutants. Mol Microbiol 48, 1511-1524.

Klockgether, J., Reva, O., Larbig, K. \& Tummler, B. (2004). Sequence analysis of the mobile genome island pKLC102 of Pseudomonas aeruginosa C. J Bacteriol 186, 518-534.

Koch, C. \& Hoiby, N. (1993). Pathogenesis of cystic fibrosis. Lancet 341, 1065-1069.

Kosorok, M. R., Zeng, L., West, S. E., Rock, M. J., Splaingard, M. L., Laxova, A., Green, C. G., Collins, J. \& Farrell, P. M. (2001). Acceleration of lung disease in children with cystic fibrosis after Pseudomonas aeruginosa acquisition. Pediatr Pulmonol 32, 277-287.

Kukavica-lbrulj, I., Bragonzi, A., Paroni, M., Winstanley, C., Sanschagrin, F., O'Toole, G. A. \& Levesque, R. C. (2008). In vivo growth of Pseudomonas aeruginosa strains PAO1 and PA14 and the hypervirulent strain LESB58 in a rat model of chronic lung infection. J Bacteriol 190, 2804-2813.

Lamont, I. L., Beare, P. A., Ochsner, U., Vasil, A. I. \& Vasil, M. L. (2002). Siderophore-mediated signaling regulates virulence factor production in Pseudomonas aeruginosa. Proc Natl Acad Sci U S A 99, 7072-7077.

Lewis, D. A., Jones, A., Parkhill, J., Speert, D. P., Govan, J. R., Lipuma, J. J., Lory, S., Webb, A. K. \& Mahenthiralingam, E. (2005). Identification of DNA markers for a transmissible Pseudomonas aeruginosa cystic fibrosis strain. Am J Respir Cell Mol Biol 33, 56-64.

Mack, K. \& Titball, R. W. (1998). The detection of insertion sequences within the human pathogen Burkholderia pseudomallei which have been identified previously in Burkholderia cepacia. FEMS Microbiol Lett 162, 69-74.
Manos, J., Artimovich, E. \& Belas, R. (2004). Enhanced motility of a Proteus mirabilis strain expressing hybrid FlaAB flagella. Microbiology 150, 1291-1299.

Mathee, K., Narasimhan, G., Valdes, C., Qiu, X., Matewish, J. M., Koehrsen, M., Rokas, A., Yandava, C. N., Engels, R. \& other authors (2008). Dynamics of Pseudomonas aeruginosa genome evolution. Proc Natl Acad Sci U S A 105, 3100-3105.

McCallum, S. J., Gallagher, M. J., Corkill, J. E., Hart, C. A., Ledson, M. J. \& Walshaw, M. J. (2002). Spread of an epidemic Pseudomonas aeruginosa strain from a patient with cystic fibrosis (CF) to non-CF relatives. Thorax 57, 559-560.

Nouwens, A. S., Beatson, S. A., Whitchurch, C. B., Walsh, B. J., Schweizer, H. P., Mattick, J. S. \& Cordwell, S. J. (2003). Proteome analysis of extracellular proteins regulated by the las and rhl quorum sensing systems in Pseudomonas aeruginosa PAO1. Microbiology 149, 1311-1322.

O'Carroll, M. R., Syrmis, M. W., Wainwright, C. E., Greer, R. M., Mitchell, P., Coulter, C., Sloots, T. P., Nissen, M. D. \& Bell, S. C. (2004). Clonal strains of Pseudomonas aeruginosa in paediatric and adult cystic fibrosis units. Eur Respir J 24, 101-106.

O’Toole, G. A. \& Kolter, R. (1998). Flagellar and twitching motility are necessary for Pseudomonas aeruginosa biofilm development. Mol Microbiol 30, 295-304.

Ochsner, U. A., Wilderman, P. J., Vasil, A. I. \& Vasil, M. L. (2002). GeneChip expression analysis of the iron starvation response in Pseudomonas aeruginosa: identification of novel pyoverdine biosynthesis genes. Mol Microbiol 45, 1277-1287.

Panagea, S., Winstanley, C., Walshaw, M. J., Ledson, M. J. \& Hart, C. A. (2005). Environmental contamination with an epidemic strain of Pseudomonas aeruginosa in a Liverpool cystic fibrosis centre, and study of its survival on dry surfaces. J Hosp Infect 59, 102-107.

Pandey, D. P. \& Gerdes, K. (2005). Toxin-antitoxin loci are highly abundant in free-living but lost from host-associated prokaryotes. Nucleic Acids Res 33, 966-976.

Pellegrino, F. L., Casali, N., Dos Santos, K. R., Nouer, S. A., Scheidegger, E. M., Riley, L. W. \& Moreira, B. M. (2006). Pseudomonas aeruginosa epidemic strain carrying bla $a_{\mathrm{SPM}}$ metallo- $\beta$-lactamase detected in Rio de Janeiro, Brazil. J Chemother 18, 151-156.

Platt, M. D., Schurr, M. J., Sauer, K., Vazquez, G., Kukavica-Ibrulj, I., Potvin, E., Levesque, R. C., Fedynak, A., Brinkman, F. S. \& other authors (2008). Proteomic, microarray, and signature-tagged mutagenesis analyses of anaerobic Pseudomonas aeruginosa at $\mathrm{pH}$ 6.5, likely representing chronic, late-stage cystic fibrosis airway conditions. J Bacteriol 190, 2739-2758.

Ravin, V., Ravin, N., Casjens, S., Ford, M. E., Hatfull, G. F. \& Hendrix, R. W. (2000). Genomic sequence and analysis of the atypical temperate bacteriophage N15. J Mol Biol 299, 53-73.

Romling, U., Schmidt, K. D. \& Tummler, B. (1997). Large genome rearrangements discovered by the detailed analysis of 21 Pseudomonas aeruginosa clone $\mathrm{C}$ isolates found in environment and disease habitats. J Mol Biol 271, 386-404.

Salunkhe, P., Smart, C. H., Morgan, J. A., Panagea, S., Walshaw, M. J., Hart, C. A., Geffers, R., Tummler, B. \& Winstanley, C. (2005). A cystic fibrosis epidemic strain of Pseudomonas aeruginosa displays enhanced virulence and antimicrobial resistance. J Bacteriol 187, 4908-4920.

Sauer, K., Camper, A. K., Ehrlich, G. D., Costerton, J. W. \& Davies, D. G. (2002). Pseudomonas aeruginosa displays multiple phenotypes during development as a biofilm. J Bacteriol 184, 1140-1154.

Scharfman, A., Arora, S. K., Delmotte, P., Van Brussel, E., Mazurier, J., Ramphal, R. \& Roussel, P. (2001). Recognition of Lewis $\mathrm{x}$ 
derivatives present on mucins by flagellar components of Pseudomonas aeruginosa. Infect Immun 69, 5243-5248.

Schirmer, A. \& Jendrossek, D. (1994). Molecular characterization of the extracellular poly(3-hydroxyoctanoic acid) $[\mathrm{P}(3 \mathrm{HO})]$ depolymerase gene of Pseudomonas fluorescens GK13 and of its gene product. J Bacteriol 176, 7065-7073.

Schuster, M., Lostroh, C. P., Ogi, T. \& Greenberg, E. P. (2003). Identification, timing, and signal specificity of Pseudomonas aeruginosa quorum-controlled genes: a transcriptome analysis. J Bacteriol 185, 2066-2079.

Scott, F. W. \& Pitt, T. L. (2004). Identification and characterization of transmissible Pseudomonas aeruginosa strains in cystic fibrosis patients in England and Wales. J Med Microbiol 53, 609-615.

Shen, J., Meldrum, A. \& Poole, K. (2002). FpvA receptor involvement in pyoverdine biosynthesis in Pseudomonas aeruginosa. J Bacteriol 184, 3268-3275.

Smyth, G. (2003). Statistical issues in cDNA microarray data analysis. In Functional Genomics: Methods and Protocols, pp. 111-136. Edited by M. J. Brownstein \& A. B. Khodursky. Totowa, NJ: Humana Press.

Smyth, G. K. (2004). Linear models and empirical Bayes methods for assessing differential expression in microarray experiments. Stat Appl Genet Mol Biol 3 (article 3).

Stover, C. K., Pham, X. Q., Erwin, A. L., Mizoguchi, S. D., Warrener, P., Hickey, M. J., Brinkman, F. S., Hufnagle, W. O., Kowalik, D. J. \& other authors (2000). Complete genome sequence of Pseudomonas aeruginosa PA01, an opportunistic pathogen. Nature 406, 959-964.
Suh, S. J., Silo-Suh, L., Woods, D. E., Hassett, D. J., West, S. E. \& Ohman, D. E. (1999). Effect of rpoS mutation on the stress response and expression of virulence factors in Pseudomonas aeruginosa. $J$ Bacteriol 181, 3890-3897.

Tenover, F. C., Arbeit, R. D., Goering, R. V., Mickelsen, P. A., Murray, B. E., Persing, D. H. \& Swaminathan, B. (1995). Interpreting chromosomal DNA restriction patterns produced by pulsed-field gel electrophoresis: criteria for bacterial strain typing. J Clin Microbiol 33, 2233-2239.

Van Alst, N. E., Picardo, K. F., Iglewski, B. H. \& Haidaris, C. G. (2007). Nitrate sensing and metabolism modulate motility, biofilm formation, and virulence in Pseudomonas aeruginosa. Infect Immun 75, 3780-3790.

Wagner, V. E., Bushnell, D., Passador, L., Brooks, A. I. \& Iglewski, B. H. (2003). Microarray analysis of Pseudomonas aeruginosa quorumsensing regulons: effects of growth phase and environment. J Bacteriol 185, 2080-2095.

Waite, R. D., Papakonstantinopoulou, A., Littler, E. \& Curtis, M. A. (2005). Transcriptome analysis of Pseudomonas aeruginosa growth: comparison of gene expression in planktonic cultures and developing and mature biofilms. J Bacteriol 187, 6571-6576.

Webb, J. S., Lau, M. \& Kjelleberg, S. (2004). Bacteriophage and phenotypic variation in Pseudomonas aeruginosa biofilm development. J Bacteriol 186, 8066-8073.

Whiteley, M., Bangera, M. G., Bumgarner, R. E., Parsek, M. R., Teitzel, G. M., Lory, S. \& Greenberg, E. P. (2001). Gene expression in Pseudomonas aeruginosa biofilms. Nature 413, 860-864. 